\title{
Immune complexes can dampen inflammatory signaling at the mucosal surface during protective SIV vaccination
}

\author{
AJ Smith ${ }^{1 *}$, SW Wietgrefe ${ }^{1}$, CS Reilly¹, PJ Southern ${ }^{1}$, L Duan ${ }^{1}$, KE Perkey ${ }^{1}$, L Shang ${ }^{1}$, R Johnson², AT Haase ${ }^{1}$ \\ From AIDS Vaccine 2012 \\ Boston, MA, USA. 9-12 September 2012
}

\section{Background}

The long-term goal for an efficacious HIV vaccine is to provide sterilizing protection from HIV infection. Thus far, this scenario has only been achieved experimentally using live-attenuated SIV vaccines. As such, great interest lies in identifying correlates of protection from a successful host response to pathogenic SIV. To this end, we have used a global genomics approach, tissue analysis, and explant cultures to identify immune complex (IC) signaling as an important component of a protective host response in the female reproductive tract (FRT) of animals vaccinated with the live-attenuated virus known as SIV mac239 $\Delta$ Nef.

\section{Methods}

RNA from cervical tissue was purified for microarray analysis. Significant genes were functionally classified and protein expression determined using single-cell analytical procedures for tissue sections. FRT tissue was removed from healthy, uninfected, adult Rhesus macaques and cervix isolated/dissected into small tissue pieces for ex vivo culturing. WT $\operatorname{SIV}_{\text {mac251 }} 32 \mathrm{H}$ alone or SIV-specific ICs were added drop-wise to mucosal surfaces of explants and incubated for $24 \mathrm{hr}$ at $37^{\circ} \mathrm{C} / 5 \%$ $\mathrm{CO}_{2}$.

\section{Results}

A genome-wide transcriptomics analysis revealed selective enrichment of an anti-inflammatory program upon virus exposure in $\mathrm{SIV}_{\text {mac239- }} \Delta \mathrm{Nef}$-vaccinated animals, with localized expression of these anti-inflammatory mediators in the mucosal epithelium of the FRT, coinciding with dampened inflammation, limited $\mathrm{CD} 4^{+}$ $\mathrm{T}$ cell infiltration, and stunted virus replication. Explant cultures derived from the FRT of Rhesus macaques were used as a physiological platform to identify the inhibitory Fc receptor for IgG, Fc $\gamma$ RIIB, and carbohydrates in the Fc portion of SIV-specific ICs as centrally important in mediating this anti-inflammatory signaling program in mucosal epithelial cells.

\section{Conclusion}

These results highlight an unappreciated, non-neutralizing role for antiviral antibodies at mucosal surfaces and implicates the mucosal epithelial cell as an important host sensor that integrates external signals to elicit a host program that either promotes (inflammatory) or suppresses (anti-inflammatory) immunodeficiency virus infection.

\section{Author details}

'University of Minnesota, Minneapolis, MN, USA. ${ }^{2}$ New England Primate Research Center, Southborough, MA, USA.

Published: 13 September 2012

doi:10.1186/1742-4690-9-S2-019

Cite this article as: Smith et al:: Immune complexes can dampen inflammatory signaling at the mucosal surface during protective SIV vaccination. Retrovirology 2012 9(Suppl 2):019.

'University of Minnesota, Minneapolis, MN, USA

Full list of author information is available at the end of the article

(c) 2012 Smith et al; licensee BioMed Central Ltd. This is an Open Access article distributed under the terms of the Creative Commons 